\title{
Interventional repair of pseudoaneurysm of ascending aorta following prosthetic aortic valve replacement
}

Amer Harky, ${ }^{1}$ Amir Khosravi, ${ }^{1}$ Jonathan Colledge, ${ }^{2}$ Shyamsunder Kolvekar ${ }^{1}$

'Department of Cardiothoracic Surgery, Barts Heart Centre, St Bartholomew's Hospital, London, UK

${ }^{2}$ Department of Radiology, Barts Heart Centre, St Bartholomew's Hospital, London, UK

\section{Correspondence to}

Amer Harky,

aaharky@gmail.com

Accepted 20 January 2017

\section{DESCRIPTION}

Ascending aorta pseudoaneurysm is a high-risk complication post cardiac surgery. ${ }^{1}$ Although surgical repair is the conventional method of treatment, it is associated with a high mortality rate of $30 \%$ and a very poor prognosis. ${ }^{2}$ We report an old man aged 85 years who underwent elective biological aortic valve replacement for severe aortic valve stenosis and closure of left atrial appendage with AtriClip. Cardiopulmonary bypass was established with standard ascending aorta and right atrial cannulations. The aortic valve was replaced with $27 \mathrm{~mm}$ Hancock II type using 2/0 Ethibond pledgetted sutures in interrupted suture techniques. His

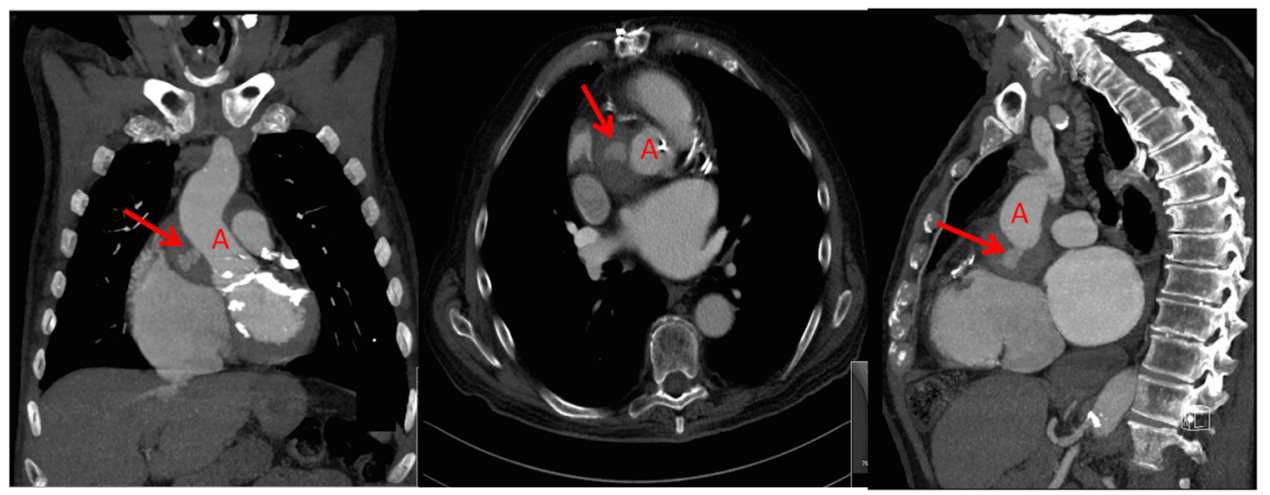

Figure 1 Enhanced contrast CT scan of the thorax showing pseudoaneurysm (arrow) arising from the ascending aorta (A).

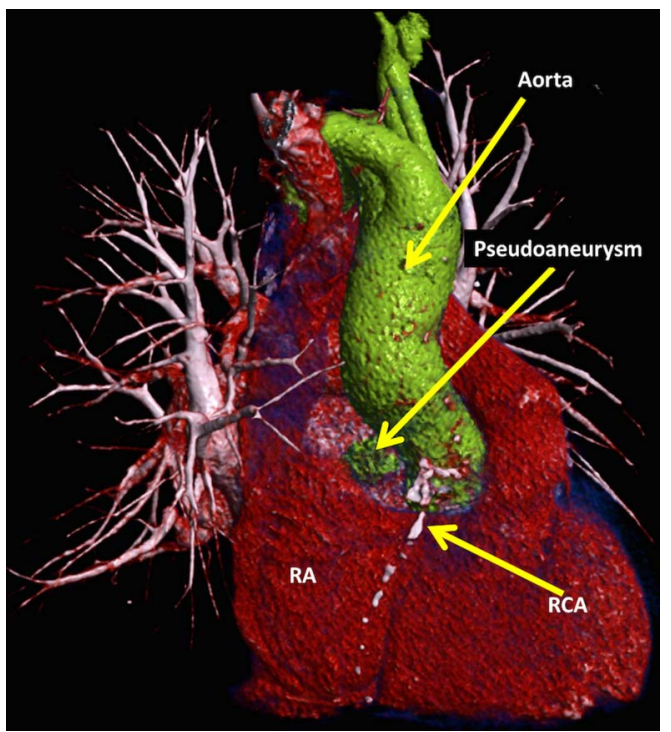

Figure 2 Three-dimensional reconstruction of CT thorax showing the pseudoaneurysm behind the right atrium (RA). RCA, right coronary artery.

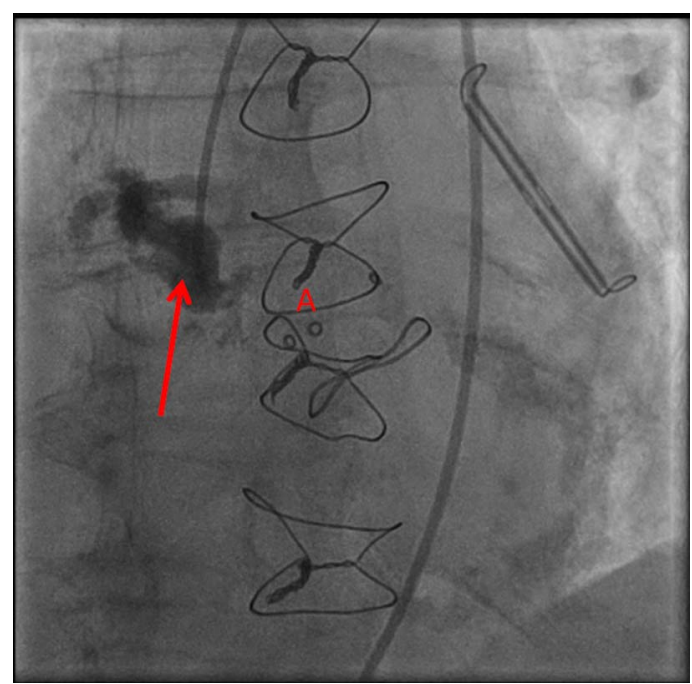

Figure 3 Intraprocedure angiogram showing location of the pseudoaneurysm (arrow) arising from the ascending aorta (A). 


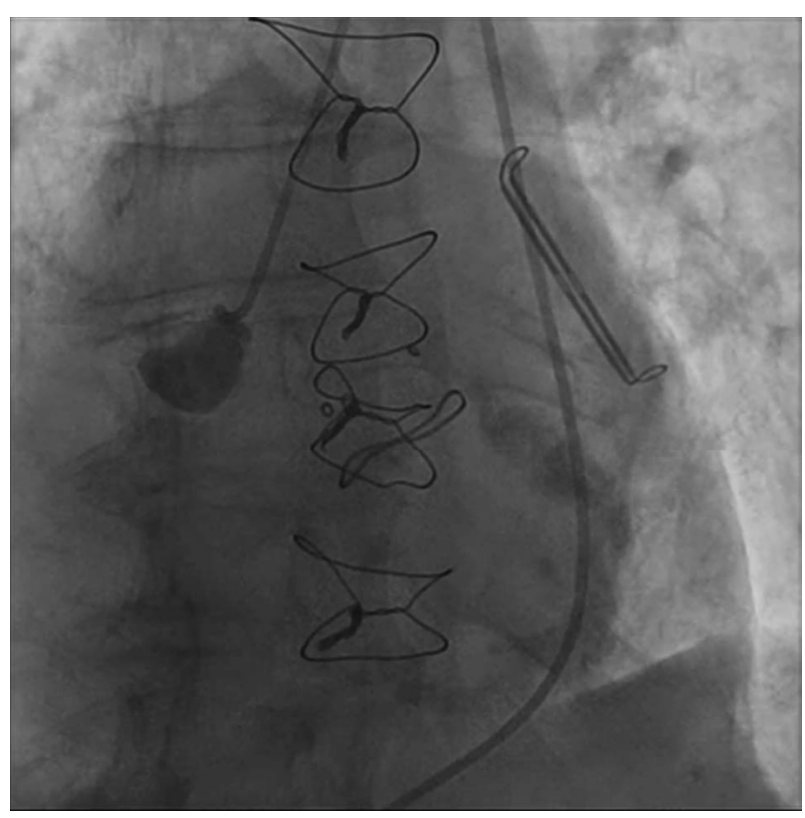

Video 1 Pseudoaneurysm of the ascending aorta prior to device deployment.

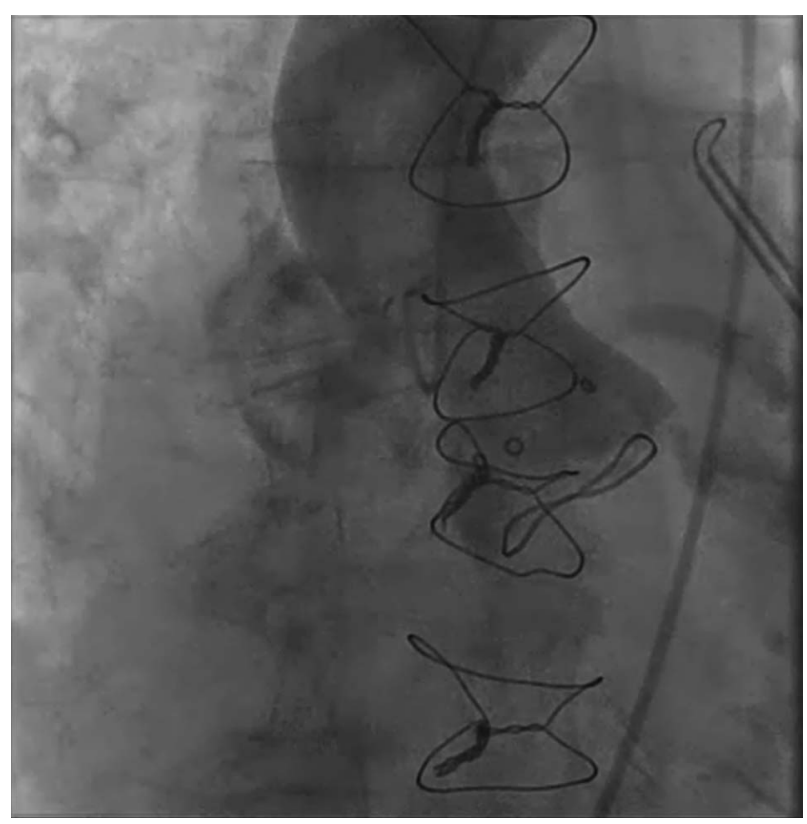

Video 2 Successfully occluded pseudoaneurysm.

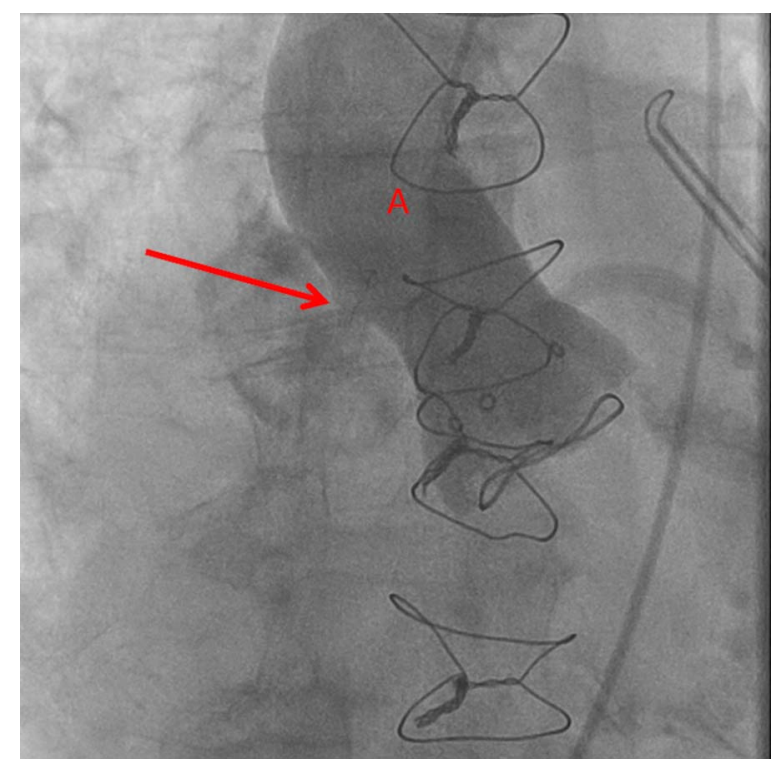

Figure 4 Intraprocedure angiogram showing successful closure of the pseudoaneurysm (arrow) that arise from the ascending aorta (A).

medical history included arterial hypertension and atrial fibrillation on rivaroxaban. Despite uneventful postoperative recovery and no symptoms at his follow-up, he presented 4 months later with sternal tenderness and soft tissue swelling at the midpart of sternotomy wound; oral antibiotic was started at that stage and he was discharged home. Two months later, he was referred to the cardiothoracic surgery unit with a sticky dark blood stained discharge from the same swelling with stable sternum.

A suspicion of ascending aortic pseudoaneurysm was confirmed with an urgent contrast chest-CT scan. This showed a large retrosternal haematoma and a $22 \mathrm{~mm}$ pseudoaneurysm arising from the ascending aorta above the non-coronary cusp of the prosthetic aortic valve (PAV) without any other pathological findings (figures 1-3, video 1 ).

After discussion in multispecialty team meeting, a nonsurgical treatment was advised. Because of the proximity of the pseudoaneurysm to PAV, a percutaneous closure was preferred to endovascular aortic repair. This was performed successfully in a hybrid cath-laboratory using a $6 \mathrm{~mm}$ Occlutech device (figure 4, video 2). Repeated contrast CT aortogram confirmed complete closure of the pseudoaneurysm (figure 5). The patient was discharged home early in good health with significant improvement of the sternal tenderness and swelling. 


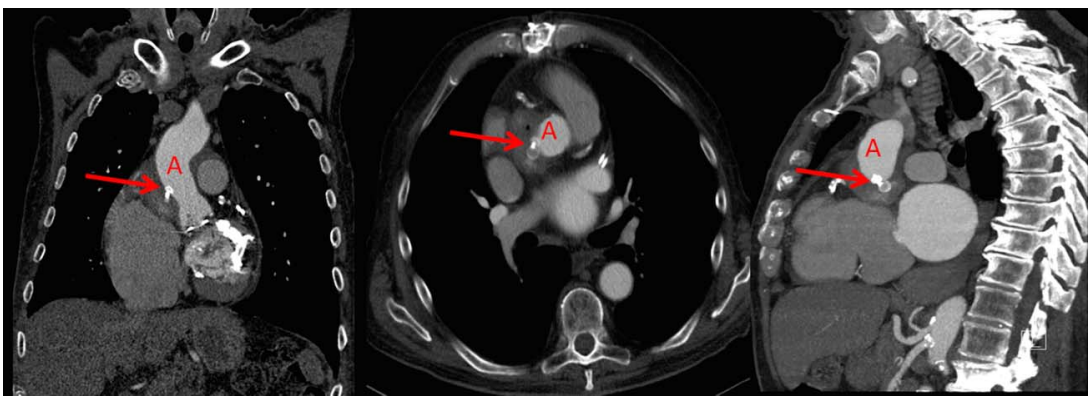

Figure 5 Contrast CT scan of the thorax showing successful occlusion of the pseudoaneurysm (arrow) that arise from the ascending aorta (A).

\section{Learning points}

- Postoperative sternal wound complications should be taken into serious consideration and early referral to the cardiothoracic surgical unit is highly recommended.

- Late heavily blood stained sternal wound discharges should raise the suspicion of retrosternal bleeding or collection.

- Non-surgical approach is recommended for treatment of aortic pseudoaneurysm post cardiac surgery.

Contributors $\mathrm{AH}$ and AK prepared and reviewed the manuscript, JC provided the necessary images for the case report and reconstructed the 3D images. SK is the responsible cardiac surgeon who operated on the patient.
Competing interests None declared.

Patient consent Obtained.

Provenance and peer review Not commissioned; externally peer reviewed.

\section{REFERENCES}

1 Razzouk A, Gundry S, Wang N, et al. Pseudoaneurysms of the aorta after cardiac surgery or chest trauma. Am Surg 1993;59:818-23.

2 Stasek J, Polansky P, Bis J, et al. The percutaneous closure of a large pseudoaneurysm of the ascending aorta with an atrial septal defect Amplatzer occluder: two-year follow-up. Can J Cardiol 2008;24:e99-101.

Copyright 2017 BMJ Publishing Group. All rights reserved. For permission to reuse any of this content visit http://group.bmj.com/group/rights-licensing/permissions.

BMJ Case Report Fellows may re-use this article for personal use and teaching without any further permission.

Become a Fellow of BMJ Case Reports today and you can:

- Submit as many cases as you like

- Enjoy fast sympathetic peer review and rapid publication of accepted articles

- Access all the published articles

- Re-use any of the published material for personal use and teaching without further permission

For information on Institutional Fellowships contact consortiasales@bmjgroup.com

Visit casereports.bmj.com for more articles like this and to become a Fellow 